\title{
High infant mortality in the big cities of Greece
}

During the last 30 years infant mortality in Greece has been falling dramatically. In 1960 of every 100 newly born infants, four died before their first birthday. By 1970 the rate had fallen to $3 \%$, in 1980 it was $1.8 \%$, and by 1987 infant mortality had come down to less than $1.2 \%$.

As the table shows, large reductions in infant mortality in Greece have occurred at a remarkable speed: within no more than 12 years infant mortality fell almost by half. On average the annual rate of change in infant mortality over the period $1976-87$ was $-5 \cdot 7 \%$.

This is clearly a success. However, satisfaction with overall progress should not make us overlook more specific aspects of this development that involve significant difficulties. Perhaps the most important of all is the level of infant mortality in the big cities: the capital city of Athens with 3 million people, and the northern city of Salonica with 700000 people (in 1981, the year of the last census).

The table makes it clear that the monotonic decrease of infant mortality rates in Greece as a whole is not reflected in a parallel development in Athens. Not only has infant mortality in the capital remained above the national average over the entire period, but there have also been years of rising rates against the national trend: in 1979, 1982, 1984-85, and 1987.

The case of Salonica gives even more cause for concern. Infant mortality in 1976-77 was below the national average, but a rise of two per 1000 live births in 1978 and a sharp increase in the early 1980 s (from 18.6 in 1982 to 25.2 in 1985) brought current ratios of infant mortality to higher levels than 15 years ago!

Average levels of infant mortality per 1000 live births during the entire 12 year period under consideration were found to be 18.99 in Athens and 21.00 in Salonica, compared with 16.66 in the country as a whole. Mean annual rates of change were $-4.2 \%$ in Athens, $+0.8 \%$ in Salonica, and (as already mentioned before) $-5.7 \%$ in Greece as a total.

Not only does this show that Athens and Salonica experience considerably higher rates of infant mortality than the national average, but also that the gap is widening: in Athens the pace of reductions is slower than in the rest of the country (and, as the table shows, is further slowing down), while in Salonica the trend is upwards.

The high levels of infant mortality in the largest cities of Greece are difficult to explain. Certainly
Infant mortality per 1000 live births in Greece

\begin{tabular}{llll}
\hline Year & Greece & Athens & Salonica \\
\hline 1976 & 22.48 & 24.99 & 19.95 \\
1977 & 20.35 & 21.52 & 19.65 \\
1978 & 19.24 & 20.48 & 21.63 \\
1979 & 18.60 & 21.42 & 21.41 \\
1980 & 17.92 & 19.66 & 20.12 \\
1981 & 16.23 & 18.68 & 20.74 \\
1982 & 15.00 & 19.38 & 18.60 \\
1983 & 14.51 & 15.34 & 20.33 \\
1984 & 14.31 & 16.45 & 22.81 \\
1985 & 14.10 & 16.91 & 25.16 \\
1986 & 11.99 & 13.94 & 21.80 \\
1987 & 11.62 & 14.74 & 20.97 \\
\hline
\end{tabular}

Source: Office National de Statistique de Grèce, Mouvement naturel de la population de la Grèce, Athens [several years]

the cities are far from disadvantaged in terms of medical care availability: in the early 1980s there were more paediatricians and obstetricians in Salonica than in Athens, and more than twice as many as in Greece as a whole. Prosperity indicators leave no doubt that Greater Athens is the wealthiest "region" in Greece, closely followed by Salonica. Education standards are also higher: more than $60^{\circ}{ }_{0}$ of females at maternity age (15-44 years) in Athens, and more than $50 \%$ in Salonica have completed at least the compulsory minimum of nine schooling years, compared with a national average of $44^{\circ}{ }_{0}$. By all accounts Athens and Salonica have all the characteristics of a modern European society that enjoys high standards of living, satisfactory levels of educational achievement, and easy access to medical care. In other words, exactly the places where one would least expect to find high rates of infant mortality.

The reasons for this paradox are not clear. The contribution this article is hoped to make is not to provide the answers but to point to an area that needs further research. Having said that, I would like to conclude with a few observations:

(a) The trends reviewed above illustrate that the relationship between availability of medical care and infant mortality is not as straightforward as some would have us believe. In the big cities of Greece high mortality rates coexist with large numbers of doctors. The rest of the country suffers from a serious lack of doctors and hospital beds but enjoys considerably lower rates of infant mortality.

(b) It seems possible that indiscriminate use of modern delivery techniques (such as caesarean sections) has a harmful effect on infant survival prospects. Whether this can be held as a reason for higher infant mortality rates in the big cities 
where most high technology maternity hospitals operate can only be answered with specific research into the issue. However, there is a case for a shift of emphasis towards a more vigorous monitoring of the quality and effectiveness of procedures routinely applied in most hospitals.

(c) The hypothesis of a negative relationship between socioeconomic status and infant mortality does not seem to offer an adequate explanation for the distribution of the latter in Greece. Athens and Salonica enjoy relative prosperity and high education standards as well as satisfactory access to medical services.

(d) It is quite likely that it is in the way of life where the key for an explanation lies. Cigarette consumption in Greece is by far the highest in Europe, and the proportion of female smokers is higher in the urban setting of Athens and Salonica than in the rest of the country.

(e) A further possible reason for the high levels of infant mortality in the big cities in Greece is the quality of the environment. Athens is one of the most polluted cities in the world, and in recent years Salonica has been facing a similar deterioration. Although it is difficult to explain the rise of infant mortality rates in Salonica by exclusive reference to pollution, environmental factors certainly look as if they are part of the problem.

In view of the above there seems to be a strong case for a shift in the policy debate away from the generalities of organisation and financing, and towards a consideration of specific issues and a search for effective policies. For this to happen it is necessary that those working in the broad area of health policy in Greece demand a say in decisions that affect health but have been traditionally regarded as the prerogative of other Ministries. A greater involvement of health policy makers in matters of taxation, urban planning or transport may result in a re-setting of the agenda in health that should be welcomed as a development from which the country can only benefit.

I thank Eleni Apostolidou and Stelios Katranidis for their assistance in data collection. Dimitris Niakas made many useful suggestions for which I am grateful.

Manos Matsaganis Welfare State Programme London School of Economics Houghton Street London WC2A 2AE United Kingdom 